\title{
Visually induced analgesia during face or limb stimulation in healthy and migraine subjects
}

\section{Simona Liliana Sava' \\ Victor de Pasqua ${ }^{2}$ \\ Alain Maertens de \\ Noordhout ${ }^{2}$ \\ Jean Schoenen ${ }^{2}$}

'Headache Clinic of Valdor - ISOSL, Liège, Belgium; ${ }^{2}$ Headache Research Unit, Department of Neurology, Liège University, Liège, Belgium
Correspondence: Simona Liliana Sava Headache Clinic of Valdor, Rue de BasseWez 145, 4020 Liège, Belgium

Tel +32 434 I 8400

Email simonaliliana.sava@gmail.com
This article was published in the following Dove Press journal: Journal of Pain Research

Background: Visually induced analgesia (VIA) defines a phenomenon in which viewing one's own body part during its painful stimulation decreases the perception of pain. VIA occurs during direct vision of the stimulated body part and also when seeing it reflected in a mirror. To the best of our knowledge, VIA has not been studied in the trigeminal area, where it could be relevant for the control of headache.

Subjects and methods: We used heat stimuli $\left(53^{\circ} \mathrm{C}\right)$ to induce pain in the right forehead or wrist in 11 healthy subjects (HSs) and 14 female migraine without aura (MO) patients between attacks. The subjects rated pain on a visual analog scale (VAS) and underwent contact heatevoked potential (CHEP) recordings (five sequential blocks of four responses) with or without observation of their face/wrist in a mirror.

Results: During wrist stimulation, amplitude of the first block of P1-P2 components of CHEPs decreased compared to that in the control recording when HSs were seeing their wrist reflected in the mirror ( $p=0.036 ; Z=2.08$ ); however, this was not found in MO patients. In the latter, the VAS pain score increased viewing the reflected wrist $(p=0.049 ; Z=1.96$ ). Seeing their forehead reflected in the mirror induced a significant increase in N2 latency of CHEPs in HSs, as well as an amplitude reduction in the first block of P1-P2 components of CHEPs both in HSs $(p=0.007 ; Z=2.69)$ and MO patients $(p=0.035 ; Z=2.10)$. Visualizing the body part did not modify habituation of CHEP amplitudes over the five blocks of averaged responses, neither during wrist nor during forehead stimulation.

Conclusion: This study adds to the available knowledge on VIA and demonstrates this phenomenon for painful stimuli in the trigeminal area, as long as CHEPs are used as indices of central pain processing. In migraine patients during interictal periods, VIA assessed with CHEPs is within normal limits in the face but absent at the wrist, possibly reflecting dysfunctioning of extracephalic pain control.

Keywords: visually induced analgesia, CHEPs, migraine, vision, pain, mirror therapy

\section{Introduction}

Cortical networks engaged in the processing of sensory stimuli largely overlap for the various sensory modalities including nociceptive stimuli. ${ }^{1}$

The latter study using functional magnetic resonance imaging (fMRI) concluded that the largest part of networks activated by phasic nociceptive stimuli reflected non-nociceptive-specific cognitive processes mainly driven by salience of the applied stimulus and showed that the extent of cortical activation was largest for the visual modality. 
Interactions between various sensory modalities (such as touch or vision) and pain processing have been suspected and partly studied for several decades, beginning with the gate control theory of Melzack and Wall. ${ }^{2}$ Hence, viewing one's own body accelerates tactile reactions, increases tactile spatial acuity, and modulates somatosensory-evoked potentials..$^{3-5}$ Touch can reduce pain levels and cortical pain processing. ${ }^{6-9}$ Finally, tactile discrimination training reduces chronic central pain, ${ }^{10,11}$ and this effect is enhanced by seeing the body. ${ }^{10-12}$

Therapeutic studies have suggested that vision of the body is able to reduce chronic phantom limb pain. ${ }^{13,14}$ In this disorder, the reflection of the damaged body part given by the mirror is thought to reorganize and integrate the mismatch between the subject's proprioception and the actual visual feedback and thus to relieve phantom limb pain, probably via slow neuroplastic changes. ${ }^{15-17}$ Recently, the mirror therapy was also effectively used for patients with complex regional pain syndrome and stroke. ${ }^{18-20}$

Longo et a ${ }^{21,22}$ have recently demonstrated the existence of a visually induced analgesia (VIA) mechanism in healthy subjects (HSs). This physiological phenomenon is characterized by the reduction in pain perception and painrelated evoked potentials during a painful infrared laser stimulation when the subject sees the area of his or her body where the painful stimulus is applied. ${ }^{21,22}$ VIA is obtained during direct vision and also when indirectly seeing the body part reflected in a mirror; however, it is absent when viewing someone else's body part. VIA was demonstrated in peripheral limbs but has not yet been studied in the face, ie, in the trigeminal area.

In migraine patients, interactions between vision and the trigeminal pain system are likely to occur. Photophobia is a hallmark of migraine attacks, but it is also prevalent between attacks. Its mechanisms have been addressed in several recent studies. ${ }^{23}$ We have recently shown in healthy volunteers that the nociception-specific blink reflex (nsBR), a trigeminal nociceptive brain stem reflex, is increased by inhibiting the visual cortex with low-frequency repetitive transcranial magnetic stimulation but decreased by visual activation with $8 \mathrm{~Hz}$ flash light stimulation, suggesting an inhibitory top-down relation between the visual cortex and second-order trigeminal nociceptors. ${ }^{24}$

Based on the assumption that pathways linking the visual and trigeminal systems might be impaired in migraine, we decided to study VIA in the trigeminal territory using thermonociceptive stimuli and comparing HSs with migraine patients between attacks.

\section{Subjects and methods Subjects}

We recruited 11 female HSs (age, $29.45 \pm 10.25$ years, mean \pm SD) and 14 patients suffering from migraine without aura (MO; code 1.1) according to ICHD-3 beta criteria (MO, 14 females; age, $26.4 \pm 4.55$ years, mean \pm SD) ${ }^{25} \mathrm{HSs}$ had no personal or familial history of primary headaches and were devoid of any significant somatic or psychiatric diseases and of any drug treatment except the contraceptive pill. They were recruited among medical students and hospital personnel. MO patients were recruited among those attending our outpatient headache clinic and were not allowed to take preventive therapy or any other drug between attacks. They suffered from migraine since $11.07 \pm 4.9$ years and had on average $2.02 \pm 1.52$ attacks per month with a mean attack duration of $21.57 \pm 17.85$ hours. They were recorded in the interictal phase, ie, they were attack free for at least 3 days before and after the recording sessions, which was verified by phone or e-mail.

To avoid changes of cortical excitability due to hormonal variations, females were recorded during mid-cycle. ${ }^{26}$

This study was approved by the local ethics committee of the CHR Citadelle Hospital, Liège, Belgium, and conducted following the principles of the Declaration of Helsinki. All participants gave written informed consent prior to testing.

\section{Methods}

We assessed heat pain using a $0-10$ visual analog scale (VAS) for the subjective evaluation of pain intensity and contact heat-evoked potentials (CHEPs) as an objective index of pain processing. ${ }^{27-30}$

\section{CHEPs}

The CHEPs stimulation unit (Medoc Ltd., Ramat Yishai, Israel) is composed of a thermode applied to the skin and covers a cutaneous area of $572.5 \mathrm{~mm}^{2}$ (diameter $27 \mathrm{~mm}$ ). The thermode comprises an external layer consisting of a heating foil and a subjacent Peltier element with two thermistors (electronic thermal sensors). The heating thermofoil (Minco Products, Inc., Minneapolis, MN, USA) is covered with a $25 \mu \mathrm{m}$ layer of thermoconductive plastic (Kapton ${ }^{\circledR}$; DuPont, Wilmington, DE, USA; thermal conductivity at $23^{\circ} \mathrm{C}$ of $0.1-0.35 \mathrm{~W} / \mathrm{m} / \mathrm{K}$ ) that separates the external foil from the skin. Two thermocouples are embedded at $10 \mu \mathrm{m}$ within this conductive coating, which is in direct contact with the skin, allowing an estimation of skin temperature at the thermode surface. ${ }^{30,31}$ 
Baseline skin temperature was kept constant at $35^{\circ} \mathrm{C}$. Twenty brief heat stimuli were delivered. The peak was set at $53^{\circ} \mathrm{C}$, the heating rate was $70^{\circ} \mathrm{C} / \mathrm{s}$, and the cooling decrement that started as soon as $53^{\circ} \mathrm{C}$ was reached was $40^{\circ} \mathrm{C} / \mathrm{s}$, for a total stimulus duration of $707 \mathrm{~ms}$. The interstimulus interval varied randomly between 10 and 22 seconds. The thermode was placed on the right volar wrist or right forehead.

The cortical responses evoked by the heat stimuli (CHEPs) were recorded using pin electrodes inserted at $\mathrm{Cz}$ (active) and $\mathrm{Fz}$ (reference) according to the international 10-20 system, with a band pass of $0.15-100 \mathrm{~Hz}\left(\mathrm{CED}^{\mathrm{TM}}\right.$ 1902 preamplifier and CED ${ }^{\mathrm{TM}}$ Micro1401 converter; Cambridge Electronic Design Ltd, Cambridge, UK). A ground electrode was fixed to the right hand. The impedance for all electrodes was kept $<5 \mathrm{k} \Omega$. Twenty responses were averaged off-line and partitioned into five blocks of four responses using Signal ${ }^{\mathrm{TM}}$ software version 4.11 (Cambridge Electronic Design Ltd). We focused on the following A $\delta$ fiber-related CHEP components identified according to latency: P1 as the first most positive point around a latency of $200 \mathrm{~ms}$ for the wrist and $150 \mathrm{~ms}$ for the face, $\mathrm{N} 2$ as the following negative peak around a latency of $280 \mathrm{~ms}$ for the wrist and $250 \mathrm{~ms}$ for the face, and P2 as the second-most positive point around a latency of $400 \mathrm{~ms}$ for the wrist and $350 \mathrm{~ms}$ for the face (Figure 1). ${ }^{32}$

Subjects were asked to rate the global heat-evoked pain on a VAS from 0 to 10 just after each series of 20 stimuli.

\section{Study protocol}

Subjects sat with open eyes in a comfortable armchair in the neurophysiological laboratory room with dimmed light. CHEPs and heat pain intensity were recorded at baseline without sight of the corresponding body part, first during stimulation of the wrist followed after \pm 10 minutes by forehead stimulation. Thereafter the recordings were repeated in the same sequence and with similar intervals while subjects were seeing the wrist or forehead in a mirror (Figure 2).

\section{Data processing and statistical analysis}

The latencies (in milliseconds) of the three CHEP components and peak-to-peak P1-N2 and N2-P2 and amplitudes (in microvolt) were measured. To assess more reliably the global brain activity generated by the thermonociceptive stimulus, we also determined the P1-P2 area under the curve (AUC; $\mu \mathrm{V} \cdot \mathrm{ms}$ ) of each block of four averaged responses. ${ }^{33}$ As we found no difference between the results obtained for amplitude and for AUC measures, we chose to report only the latter.

Habituation was defined as the change in P1-P2 AUC over the five successive blocks of averaging expressed as the slope of the linear regression line of AUC changes. In addition, we measured habituation as the percentage change in P1-P2 AUC between the fifth and the first block. The two methods yielded similar results; thus, we report only on slope values.

Statistica for Windows version 8.0 (StatSoft, Inc. Tulsa, OK, USA) was used for all statistical analyses. Wilcoxon's

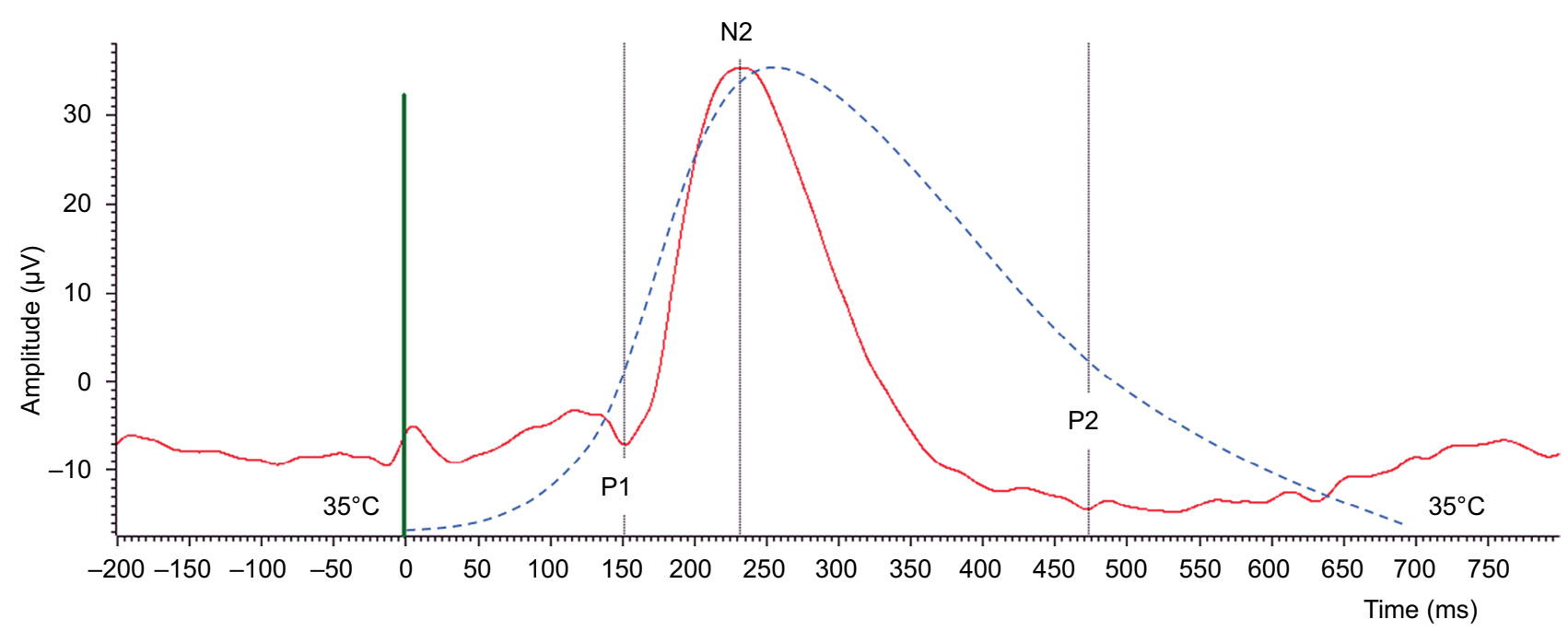

Figure I Illustrative CHEP recording (20 averaged responses) in an HS (continuous red curve). PI, N2, and P2 components are identified at, respectively, I50, 232, and $473 \mathrm{~ms}$ after the onset of the heat stimulus (green line). The dashed blue curve represents the temporal evolution of skin temperature starting at $35^{\circ} \mathrm{C}$, rising to $53^{\circ} \mathrm{C}$ after $257 \mathrm{~ms}$ at a speed of $70^{\circ} \mathrm{C} / \mathrm{s}$, and returning to baseline at $40^{\circ} \mathrm{C} / \mathrm{s}$.

Abbreviations: CHEP, contact heat-evoked potential; HS, healthy subject. 


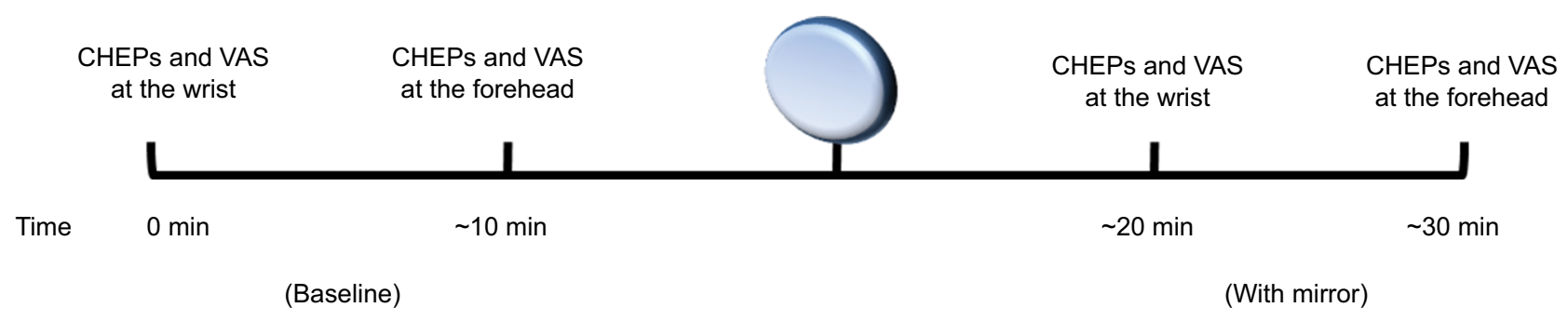

Figure 2 Protocol design.

Abbreviations: CHEP, contact heat-evoked potential; VAS, visual analog scale.

test was applied to search for differences in latencies, P1P2 AUC, and slope between baseline and mirror vision. The Mann-Whitney $U$-test was used to make comparisons between groups. The significance level was $p \leq 0.05$.

\section{Results}

Table 1 displays all experimental data as mean \pm SD values and $p$ values for changes between baseline recordings and those with vision of body part with the mirror.

All CHEP recordings obtained after right forehead stimulation were analyzable, while the recordings after wrist stimulation of two subjects (one HS and one MO) were excluded because of insufficient signal quality.

During wrist stimulation, we found a significant decrease in the first block P1-P2 AUC in HSs when they were seeing their wrist reflected in the mirror compared to the baseline recording ( $p=0.036 ; Z=2.08$; Figure $3 \mathrm{~A}$ ) where there was no change in pain ratings (Figure 3B). By contrast, in $\mathrm{MO}$ patients, using the mirror had no effect on CHEP amplitudes, but the VAS pain score increased significantly at the wrist ( $p=0.049 ; Z=1.96$; Figure 3B). There were no significant changes in $\mathrm{P} 1, \mathrm{~N} 2$, and $\mathrm{P} 2$ latencies between baseline recordings and those with the mirror (Table 2).

When the heat stimulus was applied to the forehead, there was a significant decrease in N2 latency in HSs when they watched their face in the mirror $(p=0.04 ; Z=1.99$; Table 2). In both HSs and migraine patients, using the mir-

Table I Mean demographic data \pm SD.

\begin{tabular}{lll}
\hline & HS (n= II) & MO (n= I4) \\
\hline Women (n) & $\mathrm{II}$ & 14 \\
Age (years) & $29.45 \pm 10.25$ & $26.5 \pm 4.55$ \\
Duration of history of migraine (years) & & $11.07 \pm 4.9$ \\
Attack frequency/month (n) & & $2.02 \pm 1.52$ \\
Attack duration (hours) & & $21.57 \pm 17.85$ \\
\hline
\end{tabular}

Abbreviations: $\mathrm{HS}$, healthy subject; $\mathrm{MO}$, migraine without aura; SD, standard deviation. ror significantly decreased first block CHEP P1-P2 AUC ( $p=0.007 ; Z=2.69$ and $p=0.035 ; Z=2.10$, respectively; Figure 3C). Global average over all $20 \mathrm{P} 1-\mathrm{P} 2$ AUC responses was significant in HSs using the mirror with a decreased effect ( $p=0.001 ; Z=3.17$; Table 2). Conversely, there was no difference in VAS pain scores between baseline and vision with the mirror (Figure 3D).

The habituation slope of CHEP P1-P2 AUC over the five blocks of four averaged responses was not modified by seeing the wrist or forehead in the mirror in either the HSs or migraine patients (Table 2 and Figure 4).

Finally, there were no significant differences between HSs and migraine patients in any of the baseline CHEPs or pain score values.

\section{Discussion}

Our study shows that VIA can be demonstrated in healthy and migraine subjects in the trigeminal area, as far as CHEPs are used as indices of central pain processing. In healthy volunteers, but not in migraine patients, we also found that VIA for CHEPs can be obtained by thermonociceptive stimulation of the wrist, which is in line with the reports by Longo et $\mathrm{al}^{21,22}$ who used laser heat-evoked potentials.

Contrary to the latter, however, pain ratings were not significantly attenuated in our study by vision of the stimulated body part, despite a numerical decrease in pain ratings in healthy volunteers. Another difference is that all our subjects were females, while in the cohort of Longo et al, ${ }^{22}$ only three out of 14 subjects were females. Gender differences in pain perception were well documented. Women reported indeed a higher pain sensitivity with various types of noxious stimuli (eg, ischemic, pressure, electrical, and thermal), with the magnitude of gender differences depending on various factors such as sample size, nature of the noxious stimulus, or use of behavioral or verbal indices of pain sensitivity. ${ }^{34-38}$ The reason for enrolling only women in our study was that we aimed at comparing HSs with migraine patients who are predominantly females. A weakness of our study is that we 
A

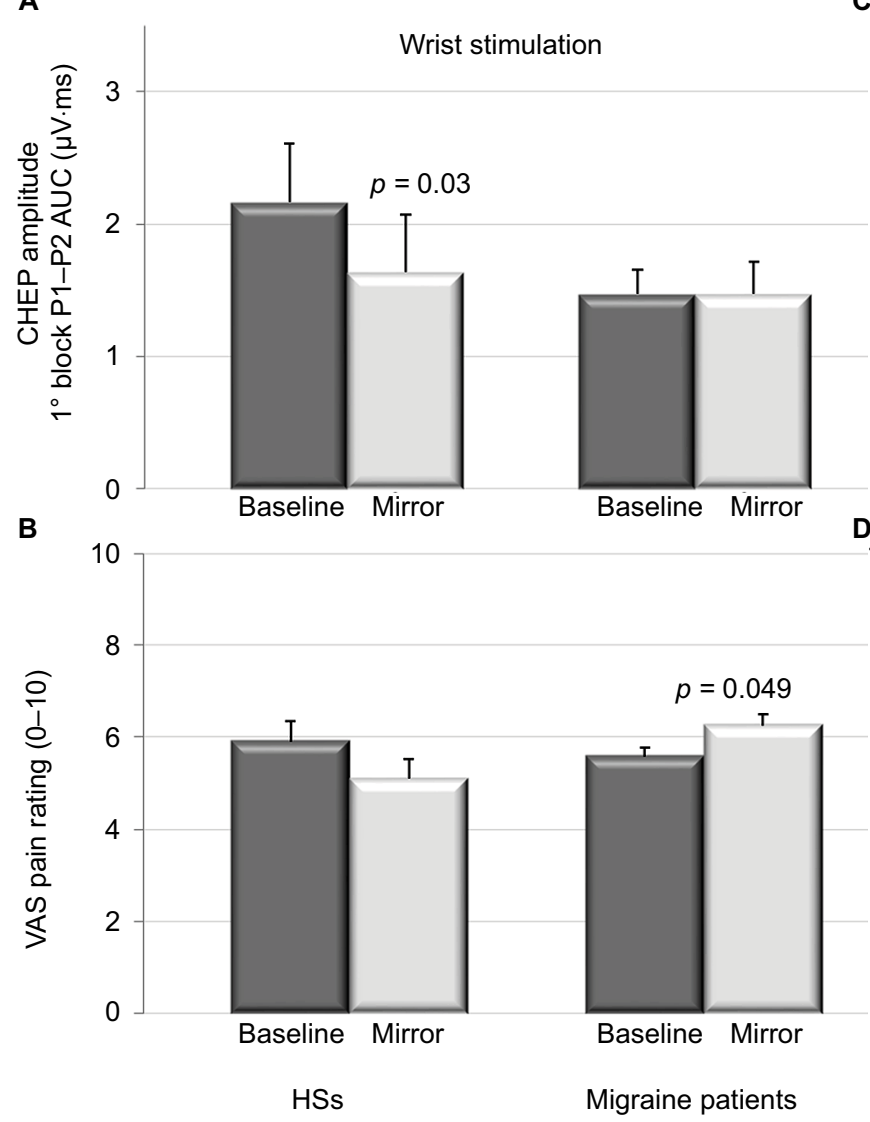

C

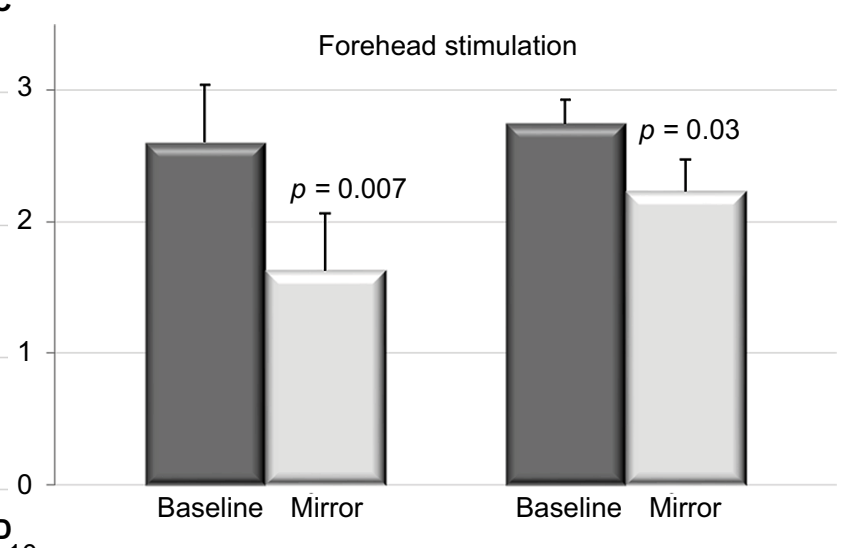

Figure 3 CHEP amplitudes (PI-P2 AUC of first block) (A and $\mathbf{C}$ ) and VAS pain ratings (B and $\mathbf{D})$ after heat stimulation at the wrist (A and $\mathbf{B})$ or forehead (C and $\mathbf{D})$ in $\mathrm{HSs}$ and migraine patients before (baseline: dark bars) and during vision of the hand or face reflected in a mirror (light bars; mean \pm SD).

Abbreviations: CHEP, contact heat-evoked potential; AUC, area under the curve; VAS, visual analog scale; HS, healthy subject.

Table 2 Synopsis of experimental data (significant changes are in bold; mean \pm SD).

\begin{tabular}{|c|c|c|c|c|c|c|}
\hline & Baseline & With mirror & $p$-value & Baseline & With mirror & $p$-value \\
\hline & \multicolumn{3}{|l|}{ HSs $(n=10)$} & \multicolumn{3}{|c|}{ MO patients $(n=13)$} \\
\hline \multicolumn{7}{|l|}{ Wrist heat stimulation } \\
\hline PI latency (ms) & $208.74 \pm 31.36$ & $212.01 \pm 48.40$ & 0.76 & $203.28 \pm 39.26$ & $192.29 \pm 44.19$ & 0.64 \\
\hline N2 latency (ms) & $272.75 \pm 39$ & $272.97 \pm 42.82$ & 0.77 & $278.54 \pm 54.25$ & $273.35 \pm 43.47$ & 0.55 \\
\hline P2 latency (ms) & $404.15 \pm 27.79$ & $388.48 \pm 27.70$ & 0.18 & $422.61 \pm 75.14$ & $403.11 \pm 74.88$ & 0.08 \\
\hline First block AUC PI-P2 ( $\mu$ V ms) & $2.17 \pm 1.38$ & $1.63 \pm 1.37$ & 0.03 & $1.47 \pm 0.66$ & $1.47 \pm 0.86$ & 0.97 \\
\hline Average on 20 responses' $\mathrm{AUC} \mathrm{PI}-\mathrm{P} 2(\mu \mathrm{V} \cdot \mathrm{ms})$ & $1.44 \pm 1.51$ & $1.22 \pm 1.07$ & 0.16 & $0.98 \pm 0.60$ & $1.03 \pm 0.65$ & 0.64 \\
\hline Slope PI-P2 over 5 blocks & $-0.27 \pm 0.18$ & $-0.20 \pm 0.17$ & 0.33 & $-0.16 \pm 0.15$ & $-0.12 \pm 0.25$ & 0.50 \\
\hline \multirow[t]{2}{*}{ VAS $(0-10)$} & $5.90 \pm 2.28$ & $5.10 \pm 2.54$ & 0.12 & $5.58 \pm 1.57$ & $6.25 \pm I .5 I$ & 0.04 \\
\hline & \multicolumn{3}{|l|}{ HSs $(n=I I)$} & \multicolumn{3}{|c|}{ MO patients $(n=14)$} \\
\hline \multicolumn{7}{|l|}{ Forehead heat stimulation } \\
\hline PI latency (ms) & $165.09 \pm 12.13$ & $160.94 \pm 31.36$ & 0.87 & $164.62 \pm 9.64$ & $162.24 \pm 11.09$ & 0.53 \\
\hline N2 latency (ms) & $247.31 \pm 19.02$ & $244.37 \pm 31.45$ & 0.049 & $253.52 \pm 36.26$ & $248.70 \pm 29.95$ & 0.85 \\
\hline P2 latency (ms) & $376.14 \pm 29.69$ & $373.24 \pm 29.98$ & 0.24 & $395.68 \pm 39.5$ & $376.46 \pm 45.83$ & 0.12 \\
\hline First block AUC PI-P2 ( $\mu$ V ms) & $2.60 \pm 1.55$ & $1.63 \pm 0.7$ & 0.007 & $2.75 \pm 1.97$ & $2.23 \pm 1.42$ & 0.03 \\
\hline Average on 20 responses' AUC PI-P2 ( $\left.\mu \mathrm{V}^{*} \mathrm{~ms}\right)$ & $\mathrm{I} .87 \pm \mathrm{I} .25$ & $1.20 \pm 0.60$ & 0.001 & $1.94 \pm 1.40$ & $1.55 \pm 0.87$ & 0.18 \\
\hline Slope PI-P2 over 5 blocks & $-0.18 \pm 0.33$ & $-0.17 \pm 0.14$ & 0.86 & $-0.20 \pm 0.38$ & $-0.21 \pm 0.27$ & 0.47 \\
\hline VAS $(0-10)$ & $5.91 \pm 1.92$ & $5.00 \pm 2.88$ & 0.26 & $5.92 \pm 2.6$ & $6.38 \pm 1.74$ & 0.47 \\
\hline
\end{tabular}

Abbreviations: $\mathrm{HS}$, healthy subject; MO, migraine without aura; AUC, area under the curve; VAS, visual analog scale. 


\section{A}

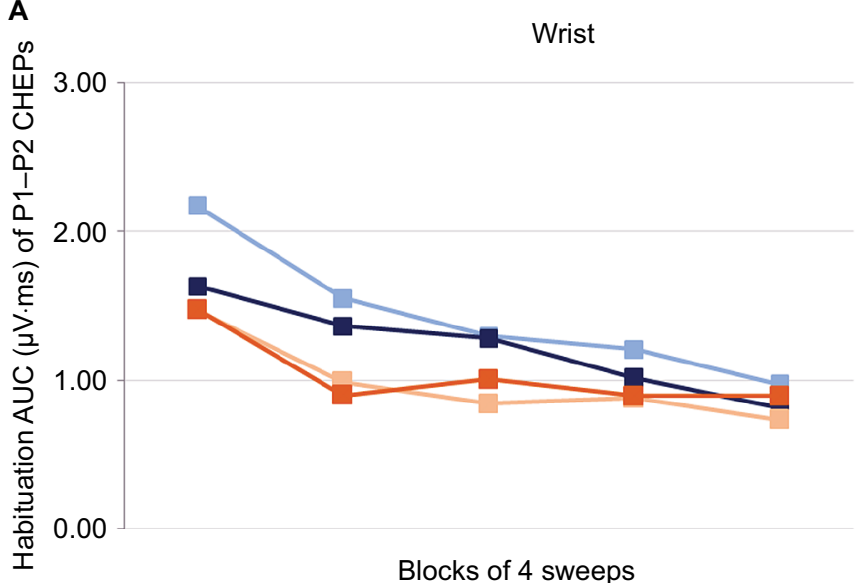

B

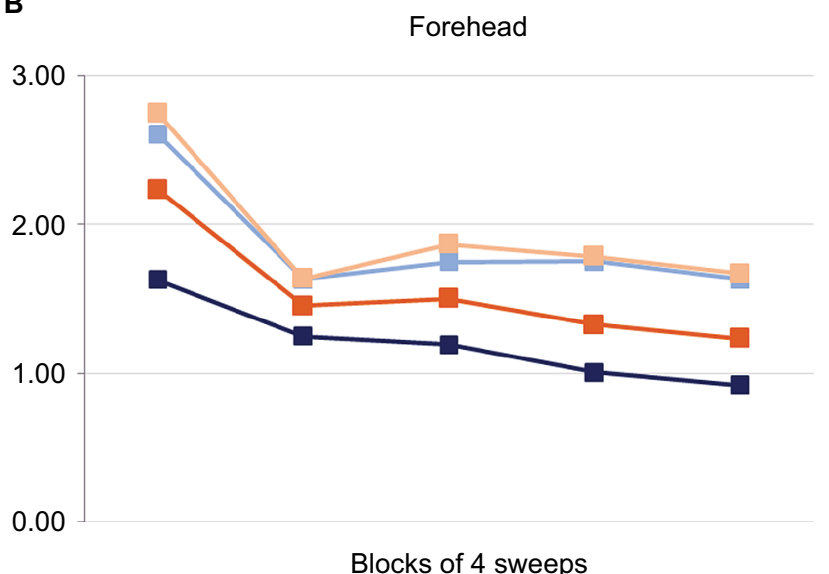

Figure 4 Habituation of CHEPs PI-P2 (AUC)over five blocks of four averaged responses in healthy women (blue) and migraine women (orange) after stimulation of the wrist (A) or the forehead (B) without (light color) and with (dark color) mirror. There was no statistical difference.

Abbreviations: CHEP, contact heat-evoked potential; AUC, area under the curve.

did not correct VAS pain ratings for certain features such as social context, BMI, and height, which can have an effect on pain perception. ${ }^{39}$

More importantly, a lack of correlation between amplitude of nociceptive-evoked cortical potentials and subjective pain perception was demonstrated in several studies undermining previous suggestions of a linear correlation between the two. ${ }^{40-42}$ Pain perception engages a complex multifocal interconnected network in the brain, while CHEPs more simply reflects activity in the cingulate gyrus. This led to the now prevailing concept that amplitude of pain-evoked potentials is driven by saliency of the stimulus rather than by pain perception. ${ }^{40,43}$

VIA is a complex phenomenon for which there are several physiological explanations. It involves chiefly the primary somatosensory cortex (SI) and the operculo-insular cortex. ${ }^{22}$ Visuotactile stimulation increases activation of the somatosensory cortex more than does touch alone. ${ }^{44}$ An fMRI study with infrared laser stimulation showed that VIA was not associated with an overall reduction in the cortical response elicited by the painful stimulus but that it increased connectivity between the brain's pain network (formerly the "pain matrix") and posterior brain areas activated by the visual perception of the body (or "visual body network"), resulting in modulation of the experience of pain. ${ }^{22}$ Recent studies have focused on the role of the extrastriate cortex in VIA. ${ }^{45}$ Interestingly, in the latter study, excitatory anodal tDCS over extrastriate areas increased the VIA phenomenon, while cathodal tDCS had no effect. These results are in line with our previous study where excitatory flash light stimulation increased the pain threshold. ${ }^{24}$
The connection between visual and somatosensory cortices is probably modulated by the thalamus. This is supported by a study showing that visual stimulation activates the orbitofrontal but not the somatosensory cortex in thalamectomized cats, suggesting that projections from the occipital cortex have to pass through the thalamus to be conveyed to the somatosensory cortex. ${ }^{46}$ Interestingly, in this study, the lateral geniculate nucleus was intact, showing that it is not an obligatory relay for visuo-somatosensory connections. However, in our work we included only MO patients. To better understand the role of the normal or dysfunctioning of visual cortex in the phenomenon of VIA, it would be of interest in future studies to explore patients suffering from migraine with visual aura and complex neurological auras.

There were several differences between HSs and migraine patients during interictal periods in our study. While in both groups, VIA was demonstrable with CHEPs derived from forehead stimulations, there was a concordant numerical decrease in pain ratings in HSs but rather an increase in migraineurs. Moreover, contrary to the former, there was no VIA for CHEPs at the wrist in the latter, and this was accompanied by a significant increase in pain scores. These results in migraine patients came as a surprise, as we expected the opposite given that sensitization of the trigeminal nociceptive system is considered a hallmark of migraine. ${ }^{47}$ Admittedly, while cranial cutaneous allodynia may persist in migraine patients between attacks, it is more prevalent during the attack and in patients with frequent or chronic migraine. ${ }^{48,49}$ In our study, the mean attack frequency was rather low (2.02/ month) and patients were recorded at a delay of at least 3 days from an attack. Hence, it is unlikely that they had persistent 
allodynia, and thus central sensitization, although this was not specifically tested. Alternatively, visual-induced decrease in pain sensitivity could be malfunctioning in patients because, as shown by various neurophysiological studies, migraine is associated between attacks with a dysfunction of temporal processing of external, especially visual, stimuli and sequential recruitment of neuronal networks, possibly related to thalamic dysrhythmia (see review by de Tommaso et $\mathrm{al}^{50}$ ). In migraine patients, extracephalic pain perception and CHEPs seem to be less amenable to the influence of body vision than their trigeminal counterparts, as shown by the comparison of wrist and forehead heat stimulation in our study. A tentative explanation for this might be a difference in the somatotopic organization of cortical networks and/or pain control mechanism.

We found that habituation of CHEPs was normal in migraine patients. This contrasts with a study of laser heatevoked potentials that did not habituate in migraine during the interictal periods but is in line with two other CHEP studies where habituation was also normal in MO between attacks. ${ }^{51-53}$ Viewing the stimulated body part through the mirror, though decreasing CHEP amplitudes, had no effect on CHEP habituation in either HSs or migraineurs.

This study has some limitations. First, the VIA phenomenon can be influenced by several other factors, in particular the attention the individual draws to the mirror, which might bias the outcome. Second, we recorded CHEP method using a fixed temperature of $53^{\circ} \mathrm{C}$, without individual adjustments according to thermal pain thresholds. Third, we did not randomize recordings with and without the mirror; hence, we cannot rule out an order effect or habituation.

\section{Conclusion}

This study adds to the available knowledge on VIA and extends this phenomenon to the face, and thus the trigeminal territory, as far as CHEPs are used as indices of central pain processing. In MO, CHEP-assessed VIA is within normal limits in the face but absent at the wrist, suggesting that between attacks, the visual modulation of extracephalic pain perception could be dysfunctioning. As in other studies, we found a lack of correlation between pain-evoked cortical potentials that were reduced by vision of the stimulated body part and subjective pain perception that remained unchanged. As mentioned in the "Introduction" section, the phenomenon of VIA has been used for therapeutic purposes in other medical conditions. In migraine, we hypothesize that this phenomenon might be useful for treating an attack, maybe as an add-on to increase efficacy of acute drug therapies. Further studies are needed to verify this hypothesis.

\section{Acknowledgment}

This study was supported by FP7-EUROHEADPAIN, no. 602633.

\section{Disclosure}

The authors report no conflicts of interest in this work.

\section{References}

1. Mouraux A, Diukova A, Lee MC, et al. A multisensory investigation of the functional significance of the "pain matrix". Neuroimage. 2011;54(3):2237-2249.

2. Melzack R, Wall PD. Pain mechanisms: a new theory. Science. 1965;150(3699):971-979.

3. Tipper SP, Lloyd D, Shorland B, Dancer C, Howard LA, McGlone F. Vision influences tactile perception without proprioceptive orienting Neuroreport. 1998;9(8):1741-1744.

4. Kennett S, Taylor-Clarke M, Haggard P. Non informative vision improves the spatial resolution of touch in humans. Curr Biol. 2001;11(15): 1188-1191.

5. Taylor-Clarke M, Kennett S, Haggard P. Vision modulates somatosensory cortical processing. Curr Biol. 2002;12:233-236.

6. Wall PD, Sweet WH. Temporary abolition of pain in man. Science. 1967;155(3758):108-109.

7. Higgens JD, Tursky B, Schwartz GE. Shock-elicited pain and its reduction by concurrent tactile stimulation. Science. 1971;172(3985):866-867.

8. Lundeberg T. Relief of pain from a phantom limb by peripheral stimulation. J Neurol. 1985;232(2):79-82.

9. Inui K, Tsuji T, Kakigi R. Temporal analysis of cortical mechanisms for pain relief by tactile stimuli in humans. Cereb Cortex. 2006;16(3) 355-365.

10. Flor H, Denke C, Schaefer M, et al. Effect of sensory discrimination training on cortical reorganization and phantom limb pain. Lancet 2001;357:1763-1764.

11. Moseley GL, Zalucki NM, Wiech K. Tactile discrimination, but not tactile stimulation alone, reduces chronic limb pain. Pain. 2008;137:600-608.

12. Moseley GL, Wiech $\mathrm{K}$. The effect of tactile discrimination training is enhanced when patients watch the reflected image of their unaffected limb during training. Pain. 2009;144(3):314-319.

13. Ramachandran VS, Rogers-Ramachandran D. Synaesthesia in phantom limbs induced with mirrors. Proc Biol Sci. 1996;263(1369):377-386.

14. Chan BL, Witt R, Charrow AP, et al. Mirror therapy for phantom limb pain. N Engl J Med. 2007;357:2206-2207.

15. Weeks SR, Anderson-Barnes VC, Tsao JW. Phantom limb pain: theories and therapies. Neurologist. 2010;16:277-286.

16. Kawashima N, Mita T, Yoshikawa M. Inter-individual difference in the effect of mirror reflection-induced visual feedback on phantom limb awareness in forearm amputees. PLoS One. 2013;8(7):e69324.

17. Foell J, Bekrater-Bodmann R, Diers M, Flor H. Mirror therapy for phantom limb pain: brain changes and the role of body representation. Eur J Pain. 2014;18(5):729-739.

18. Rothgangel AS, Braun SM, Beurskens AJ, Seitz RJ, Wade DT. The clinical aspects of mirror therapy in rehabilitation: a systematic review of the literature. Int J Rehabil Res. 2001;34(1):1-13.

19. Ezendam D, Bongers RM, Jannink MJ. Systematic review of the effectiveness of mirror therapy in upper extremity function. Disabil Rehabil. 2009;31(26):2135-2149.

20. Thieme H, Mehrholz J, Pohl M, Behrens J, Dohle C. Mirror therapy for improving motor function after stroke. Stroke. 2013;44(1):e1-e2. 
21. Longo MR, Betti V, Aglioti SM, Haggard P. Visually induced analgesia: seeing the body reduces pain. J Neurosci. 2009;29(39):12125-12130.

22. Longo MR, Iannetti GD, Mancini F, Driver J, Haggard P. Linking pain and the body: neural correlates of visually induced analgesia. J Neurosci. 2012;32(8):2601-2607.

23. Noseda R, Burstein R. Migraine pathophysiology: anatomy of the trigeminovascular pathway and associated neurological symptoms, CSD, sensitization and modulation of pain. Pain. 2013;154(suppl 1).

24. Sava SL, de Pasqua V, Magis D, Schoenen J. Effects of visual cortex activation on the nociceptive blink reflex in healthy subjects. PLoS One. 2014;9(6):e100198.

25. Headache Classification Committee of the International Headache Society (IHS). The International Classification of Headache Disorders, 3rd edition (beta version). Cephalalgia. 2013;33(9):629-808.

26. de Tommaso M, Valeriani M, Sardaro M, et al. Pain perception and laser evoked potentials during menstrual cycle in migraine. J Headache Pain. 2009;10(6):423-429.

27. Magerl W, Ali Z, Ellrich J, Meyer RA, Treede RD. C- and A delta-fiber components of heat-evoked cerebral potentials in healthy human subjects. Pain. 1999;82(2):127-137.

28. Price DD. Selective activation of A-delta and $C$ nociceptive afferents by different parameters of nociceptive heat stimulation: a tool for analysis of central mechanisms of pain. Pain. 1996;68:1-3.

29. Chen AC, Niddam DM, Arendt-Nielsen L. Contact heat evoked potentials as a valid means to study nociceptive pathways in human subjects. Neurosci Lett. 2001;316(2):79-82.

30. Valeriani M, Le Pera D, Niddam D, Chen AC, Arendt-Nielsen L. Dipolar modelling of the scalp evoked potentials to painful contact heat stimulation of the human skin. Neurosci Lett. 2002;318(1):44-48.

31. Granovsky Y, Matre D, Sokolik A, Lorenz J, Casey KL. Thermoreceptive innervation of human glabrous and hairy skin: a contact heat evoked potential analysis. Pain. 2005;115(3):238-247.

32. Granovsky Y, Anand P, Nakae A, et al. Normative data for A $\delta$ contact heat evoked potentials in adult population: a multicenter study. Pain. 2016;157(5):1156-1163.

33. Ruscheweyh R, Emptmeyer K, Putzer D, Kropp P, Marziniak M. Reproducibility of contact heat evoked potentials (CHEPs) over a 6 months interval. Clin Neurophysiol. 2013;124(11):2242-2247.

34. Berkley KJ. Sex differences in pain. Behav Brain Sci. 1997;20:371-380.

35. Fillingim R, Edwards R, Powell T. Sex-dependent effects of reported familial pain history on recent pain complaints and experimental pain responses. Pain. 2000;86:87-94.

36. Fillingim RB, Maixner W. The influence of resting blood pressure and gender on pain responses. Psychosom Med. 1996;58(4):326-332.

37. Riley JL 3rd, Robinson ME, Wise EA, Myers CD, Fillingim RB. Sex differences in the perception of noxious experimental stimuli: a metaanalysis. Pain. 1998;74(2-3):181-187.
38. Shinal R, Fillingim R. Overview of orofacial pain: epidemiology and gender differences in orofacial pain. Dent Clin North Am. 2007;51(1): $1-18$.

39. Vigil JM, Strenth CR, Mueller AA, et al. The curse of curves: sex differences in the associations between body shape and pain expression. Hum Nat. 2015;26(2):235-254.

40. Iannetti GD, Hughes NP, Lee MC, Mouraux A. Determinants of laser-evoked EEG responses: pain perception or stimulus saliency? $J$ Neurophysiol. 2008;100(2):815-828.

41. de Tommaso M, Ricci K, Montemurno A, Vecchio E. Age-related changes in laser-evoked potentials following trigeminal and hand stimulation in healthy subjects. Eur J Pain. 2017;21(6):1087-1097.

42. Carmon A, Friedman Y, Coger R, Kenton B. Single trial analysis of evoked potentials to noxious thermal stimulation in man. Pain. 1980;8(1): 21-32.

43. Mouraux A, Iannetti GD, Plaghki L. Low intensity intra-epidermal electrical stimulation can activate A $\delta$-nociceptors selectively. Pain. 2010;150(1):199-207.

44. Dionne JK, Meehan SK, Legon W, Staines WR. Crossmodal influences in somatosensory cortex: interaction of vision and touch. Hum Brain Mapp. 2010;31(1):14-25.

45. Mancini F, Bolognini N, Haggard P, Vallar G. tDCS modulation of visually induced analgesia. J Cogn Neurosci. 2012;24(12):2419-2427.

46. Imbert M, Bignall KE. Projections visuelles corticales chez le Chat thalameclomisé à l'exception du corps genouillé latéral [Projections from the visual cortex in the thalamectomized cat with the exception of the lateral geniculate body]. J Physiol (Paris). 1965;57:252-253.

47. Coppola G, Di Lorenzo C, Schoenen J, Pierelli F. Habituation and sensitization in primary headaches. J Headache Pain. 2013;14:65.

48. Burstein R, Yarnitsky D, Goor-Aryeh I, Ransil BJ, Bajwa ZH. An association between migraine and cutaneous allodynia. Ann Neurol. 2000;47(5):614-624.

49. Manack A, Buse DC, Serrano D, Turkel CC, Lipton RB. Rates, predictors, and consequences of remission from chronic migraine to episodic migraine. Neurology. 2011;76(8):711-718.

50. de Tommaso M, Ambrosini A, Brighina F, et al. Altered processing of sensory stimuli in patients with migraine. Nat Rev Neurosci. 2014;10(3):144-155.

51. de Tommaso M, Libro G, Guido M, Losito L, Lamberti P, Livrea P. Habituation of single $\mathrm{CO} 2$ laser-evoked responses during interictal phase of migraine. J Headache Pain. 2005;6(4):195-198.

52. Lev R, Granovsky Y, Yarnitsky D. Enhanced pain expectation in migraine: EEG-based evidence for impaired prefrontal function. Headache. 2013;53(7):1054-1070.

53. Beese LC, Putzer D, Osada N, Evers S, Marziniak M. Contact heat evoked potentials and habituation measured interictally in migraineurs. J Headache Pain. 2015;16:1.
Journal of Pain Research

\section{Publish your work in this journal}

The Journal of Pain Research is an international, peer reviewed, open access, online journal that welcomes laboratory and clinical findings in the fields of pain research and the prevention and management of pain. Original research, reviews, symposium reports, hypothesis formation and commentaries are all considered for publication.

\section{Dovepress}

The manuscript management system is completely online and includes a very quick and fair peer-review system, which is all easy to use. Visit http://www.dovepress.com/testimonials.php to read real quotes from published authors. 